BNL $-47210^{\circ}$

INFORMAL. REPORT

\title{
REVIEW OF REPORTS ASSOCIATED WITH SYSTEMS OF THE K, P AND L REACTORS AT THE SAVANNAH RIVER SITE
}

M. G. COWGILL

FEBRUARY 1992

NUCLEAR WASTE AND MATERIALS TECHNOLOGY DIVISION

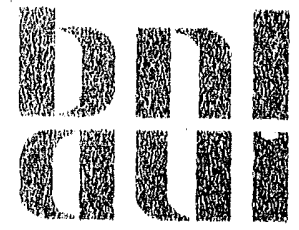

DEPARTMENT OF NUCLEAR ENERGY BROOKHAVEN NATIONAL LABORATORY, ASSOCIATED UNIVERSITIES, INC. UPTON, NEW YORK 11973

UNITED STATES DEPARTMENT OF ENERGY

CONTRACT NO. DE-ACO2-76-CH0OO16 


\section{DISCLAIMER}

This report was prepared as an account of work sponsored by an ngency of the United States Government. Neither the United Statew Government nor any agency thereof. nor any of their employees, nor any of their contractors, subcontractors, or their employees, makes any warranty, express or implied, or assumes any legal liability or responsibility for the accuracy, comploteness, or usefulness of any information, apparatus, product, or process disclosed, or represents that its use would not infringe privately owned rights. Reference herein to any specific commercial product, process, or service by trade name, trademark, manufacturer, or otherwise, does not necessarily cunstitute or imply its endorsement, recommendation, or favoring by the United states Government or any agency, contractor or subcontractor thereof. The views and opinions of authors expressed herein do not necessarily state or reflect those of the United States Government or any agency, contractor or aubcontractor thereof.

In 
REVIEW OF REPORTS ASSOCIATED WITH SYSTEMS OF THE K, P AND L REACTORS AT THE SAVANNA:I RIVER SITE

M. G. COWGILL

JANUARY 1992

NUCLEAR WASTE AND MATERIALS TECHNOLOGY DIVISION DEPARTMENT OF NUCLEAR ENERGY BROOKHAVEN NATIONAL LABORATORY UPTON, NEW YORK 11973

PREPARED FOR: OFFICE OF NUCLEAR SAFETY U. S. DEPARTMENT OF ENERGY 


\begin{abstract}
Six reports associated with the structural integrity of several systems of the Savannah River Site reactors are reviewed. The focus is on the materials-related aspects of the reports and no attempt is made to address the stress analysis-related issues.
\end{abstract}




\section{EXECUTIVE SUMMARY}

The K, P and L reactors at the Savannah River Site were shut down in 1988 so that upgrades could be made in their design, operation and management. Prior to restart of reactor operations, it is one of the requirements that assessments be provided of the structural integrity of major systems of the reactors, in order to ascertain the potential for large leaks, rapidly propagating failure and gross rupture. Supporting technical evidence of this for the process water system (PWS), the moderator recovery system (MRS) and the emergency cooling system (ECS) has been published in six topical reports. These reports have been reviewed from the materials aspects and the subsequent conclusions are presented in the present report.

In general, it is concluded that the reports provide adequate technical substantiation of the structural integrity of the systems under review. Each system is evaluated in terms of the potential for material degradation by several mechanisms, including corrosion (numerous modes), embrittlement, radiation effects, thermal aging and mechanical attack (by which the authors mean degradation due to such prosesses as fatigue, wear, erosion/corrosion and cavitation). The reports also contain stress analyses of the systems but these were beyond the scope of the present review.

In the PWS, intergranular corrosion and intergranular stress corrosion cracking in the sensitized heat-affected zones of weldments are acknowledged to be problems and have been identified as the causes of leaks in the past. Ultrasonic inspection of tank wall welds has recently been introduced and the incidence of pipe leaks due to cracking has since been considerably reduced. The inspection program has considerably reduced concern that intergranular cracks capable of leading to major leaks or ruptures will develop undetected. The potential for transgranular stress corrosion cracking, another cause of past leaks, has been essentially eliminated due to changes in practices which result in avoidance of contact with chloride-containing materials. Among other items, it is planned to upgrade the existing in-service inspection program, to bring it more into line with current commercial nuclear practices. When fully implemented, this program should prove a reliable method for continuously monitoring the condition of the PWS. There is also an effective leakmonitoring program in place which is capable of providing large margins on leak detection.

The MRS is less susceptible to the various forms of degradation than the PWS and some of the processes are virtually irrelevant. It is concluded that the majority of the corrosion processes will have a minimal to no predicted impact on its structural integrity. Minor concern was expressed about the potential for pitting corrosion in the vicinity of some flanges and it was recommended that the interfaces in question te subjected to periodic inservice inspection. The MRS as a whole is inspected and tested on a regular basis, the frequency varying with the individual component or function of interest. In summary, it can be agreed that, with the implementation of recommended modifications, the MRS will not be susceptible to major leaks or gross rupture. 
The ECS is susceptible to several forms of corrosion. Thickness losses of up to $25 \%$ of the original pipe wall (in excess of the design corrosion allowances) have been observed in some sections and it is recommended that frequent ultrasonic testing be implemented in order to more closely monitor this wall thinning. A potential exists for galvanic corrosion at dissimilar metal interfaces but such action will probably manifest itself as small leaks with no potential for gross rupture. Similarly, there is a potential for crevice corrosion at all valves and flange interfaces but, again, the likely result will be a small leak. Intergranular corrosion is not a factor for the carbon steel components but must be considered with respect to stainless steel piping, particularly near welds. Other modes of degradation, both corrosion and non-corrosion related, are relatively unimportant and cause no concern. Seismic qualification walkdowns revealed several areas in the ECS which required modification; these are to be performed prior to reactor restart. Overall, it can be concluded that the ECS is not susceptible to major leaks or rupture, assuming that all modifications required for seismic qualification are completed. It is also essential that established inspection methods and operating procedures must be adhered to, in order to manage effectively the degradation arising general and pitting corrosion. 
Pags:

ABSTRACT $\ldots \ldots \ldots \ldots \ldots \ldots \ldots \ldots \ldots \ldots \ldots \ldots \ldots \ldots \ldots \ldots \ldots$

EXECUTIVE SUMMARY $\ldots \ldots \ldots \ldots \ldots \ldots \ldots \ldots \ldots \ldots \ldots$

INTRODUCTION $\ldots \ldots \ldots \ldots \ldots \ldots \ldots \ldots \ldots \ldots \ldots \ldots$

General Description of Reactors $\ldots \ldots \ldots \ldots \ldots \ldots \ldots \ldots \ldots$

Structural Integrity of the Process Water System . . . . . . . . . . . . 2

Structural Integrity of the Moderator Recovery System . . . . . . . . .

Structural Integrity of the Emerency Cooling System . . . . . . . . . . 7

REFERENCES ........................ 11

APPENDIX A ..................... 13

APPENDIX B ....................... 17

APPENDIX C ........................ 21 


\section{INTRODUCTION}

The K, $\mathrm{P}$ and $\mathrm{L}$ reactors at the Savannah River Site (SRS) were designed, fabricated and constructed in accordance with the standard engineering practices of the late 1940s and early 1950 s, and subsequently operated safely for approximately 35 years, during which time some modifications were made. The reactors were shut down in 1988 so that upgrades could be made in their design, operation and management. Prior to restart of reactor operation, it is a requirement, among others, that assessments be provided of the structural integrity of major systems of the reactors, in order to ascertain the potential for large leaks, rapidly propagating failure or gross rupture. The reports [1-6] which are the subjects of this review provide supporting technical evidence of the structural integrity of the process water system (PWS), the moderator recovery system (MRS) and the emergency cooling system (ECS). In addition, assessments are made of the corrosion processes in the reactor systems as a whole, including the cooling water systern (CWS) and the supplemental safety system (SSS),[4], of various other degradation mechanisms [5] and of the potential for brittle failure of the carbon steel piping [6].

The present review focuses on the materials aspects of the reports and does not address any stress analysis-related issues. The main review is devoted to the structural integrity of the PWS, the MRS and the ECS on a system-by-system basis, as presented in [1-3]. The more generic reports [4-6] are reviewed in appendices.

\section{GENERAL DESCRIPTION OF REACTORS}

The three SRS reactors differ from commercial nuclear reactors in the U.S. in that they employ heavy water as the primary coolant and as the moderator for the nuclear reaction. They also operate under much less demanding conditions, with the maximum pressure in the PWS being 225 psi (at the pump discharge) and a maximum temperature at the tank outlet of approximately $203^{\circ} \mathrm{F}$. By comparison, commercial light-water reactors operate at pressures from 1000 to $2000 \mathrm{psi}$ and with coolant temperatures greater than $600^{\circ} \mathrm{F}$.

The major materials of construction for the reactor tank and the PWS are stainless steel (Types 304, 316 and their ' $L$ ' variants). Stainless steels are the only materials used in the SSS, and are also used for some piping and components of the MRS and ECS. Other materials to be found in the MRS include galvanized carbon steel (piping) and cast iron (sump pump casing and impeller). In addition to the stainless steels, the ECS contains both plain and galvanized carbon steel. The CWS is built primarily of carbon steel. Complete listings of the materials, their sizes and specifications, and their applications can be found in the subject reports, particularly [1-4]. 


\section{STRUCTURAL INTEGRITY OF THE PROCESS WATER SYSTEM}

The structural integrity of the PWS is discussed in [1]. The report provides some background information on the SRS reactors, including plant operating history, and on the adoption of the leak-before-break (LBB) methodology for the system integrity analysis. A brief section describes the stress analyses structural evaluations performed on the reactor tank and the PWS, then the results of a LBB evaluation are summarized. The development of the existing in-service inspection plan is reviewed and proposed additional new inspections detailed. Descriptions are provided of the leak monitoring program and the failure frequency probabilities estimated for the PWS piping and components, and past incidents involving cracks and leaks are reviewed. Comparison is made of the structural integrity and safety features of the SRS with the regulatory requirements for commercial nuclear reactors and a summary is provided of the safety enhancement programs.

The report does not provide details on the specifications of the materials used in the construction of the PWS or on the fabrication procedures employed. The structural material in contact with the coolant is Type 304 stainless steel in either wrought or cast form. This material is used for both the reactor tank and the many items (coclant pump, heat exchangers, expansion joints, nozzles, valves and piping) which comprise the remainder of the PWS. The maximum coolant temperature (seen at the tank outlet) is approximately $203^{\circ} \mathrm{F}$.

The report describes briefly some material degradation mechanisms and summarizes the degrees in which they might affect the materials of the PWS. Few details are provided, however, these being contained in other (referenced) sources. These other sources were not available during the present review, thus an in-depth appraisal of the validity of the various conclusions contained in the report is not possible. Thus the comments on degradation modes in the following paragraphs should be read with this limitation in mind.

Neutron (but not gamma) radiation will cause some damage in the material of the tark, of most concern being a loss in ductility. The actual extent of this damage will be dependent on the neutron fluence experienced and will vary with location in the tank. On the positive side, the material is an austenitic stainless steel and has high initial ductility and fracture toughness. Although these properties will be degraded by radiation, the steel will remain ductile up to large fluences and the report's conclusion, that the tank integrity will not be compromised on account of radiation damage, is probably valid. The report do not discuss radiation damage to the remainder of the PWS but this will be less than that experienced by the tank.

The report concludes that failure due to thermal fatigue will not occur. This is a reasonable conclusion when consideration is taken of the relatively small temperature cycles (and associated thermally-induced stresses) implicit in a system with a maximum operating temperature of about $200^{\circ} \mathrm{F}$. On the subject of mechanical fatigue, none is predicted to occur in the tank but failure due to excessive vibration has been experienced in the 
expansion joints in the PWS. Subsequent redesign of the latter components has apparently cured this problem.

Intergranular corrosion and intergranular stress corrosion cracking in sensilized heataffected zones of weldments are acknowledged potential problems. These phenomena have been identified as the causes of leaks in the past. Recent ultrasonic inspection of the tank wall welds produced no indications of significant intergranular attack in these areas and the incidence of pipe leaks due to cracking has been reduced considerably since the introduction of these inspections. Obviously, the potential for such degradation mechanisms still exists in the PWS. However, it appears that the inspection program that has been instituted has considerably reduced concern that the development of intergranular cracks which might lead to major leaks or ruptures will remain undetected.

Transgranular stress corrosion cracking has been identified as the cause of leaks in the heat exchanger tubes and header, the reactor tank effluent nozzles and large diameter piping. The cracks originated in all cases on outside surfaces of the components and were apparently promoted by chloride ions which were present in paints, inks, insulation, labels or river water. This type of cracking became less frequent after efforts were made to isolate the PWS components from chloride-containing materials. It would appear that, if current practices continue, transgranular stress corrosion cracking will be essentially eliminated as a potential failure mechanism in the PWS.

Irradiation-assisted stress corrosion cracking was also considered as a potential degradation mechanism but generally this mode of attack is observed only at temperatures of $536^{\circ} \mathrm{F}$ and above, and then only in regions exposed to a high neutron flux. It has not been encountered in the SRS reactors and it is reasonable to assume that, because of the relatively low operating temperatures, it is not a credible failure mechanism. Similarly, these low temperatures effectively eliminate concern about embrittlement due to long-term thermal aging processes.

The report does not address the possibility of wall thinning due to general corrosion, except to state that the austenitic stainless steel used is not as susceptible to this as the materials used in commercial light-water reactors. This is undoubtedly true, particularly at the much lower operating temperatures. At the same time, no attempt is made to discuss the potential for crevice corrosion, a mode which is of sorne mild concern in other systems of the SRS reactors (see [3], [4]).

The LBB analysis performed on the PWS appears to be comprehensive and to effectively demonstrate that the system will fail by leaking rather than sudden, gross rupture. The analysis is based on consideration of accepted criteria established by the Nuclear Regulatory Commission and contained in NUREG-1061. The bases for the evaluation include consideration of the effects of corrosion, performance of numerous stress analyses, demonstration that the material is not susceptible to cleavage-type fracture over the full range of operating temperatures and the provision of appropriate materials properties. 
Within the limited scope of the present review, it appears that there is considerable justification to support the conclusion that, if failure takes place in the PWS, it will manifest itself in as a leak and not a gross rupture such as a double-ended guillotine break.

The report provides details both on the existing in-service inspection program and on upgrades planned to bring the program more into line with current commercial nuclear practices. The inspection will cover all the principal component of the PWS, define the tests and examinations to be performed, and specify the frequency and extent of these tests, and the acceptance criteria. It is concluded that, if fully implemented, the inservice inspection program should prove a reliable method for continuously monitoring the condition of the PWS.

In addition to the inservice inspection program, the SRS reactors are continuously monitored for coolant leakage. The leak monitoring program involves several subsystems and the leak detection capability is reported to significantly exceed those required for commercial nuclear power plants. The program appears to have been very effective in detecting leaks and taking corrective action before the cracks could increase to a significant size. The report provides a summary of the technical specifications and operating procedures for response to leakage. Based on the information available, it is concluded that the PWS is being monitored by an effective leak-monitoring program and that the systems in place have the capability of providing large margins on leak detection which are sufficient to support LBB margins.

Of necessity, the present review of the report on the structural integrity of the PWS is limited. Within those limits, it is concluded that the subject report provides a comprehensive demonstration of the leak-before-break capability of the system. The PWS appears to have an effective inservice inspection program which will ensure, through early crack detection, that the components will not be susceptible to catastrophic failure. The PWS also includes a leak detection system capable of detecting leaks in sufficient time to allow a safe and orderly shutdown of the reactor.

\section{STRUCTURAL INTEGRITY OF THE MODERATOR RECOVERY SYSTEM}

The structural integrity of the MRS is discussed in [2]. The report is divided into several sections and provides a system description, a listing of the codes and standards employed in the design of the MRS, and surnmaries of the stress analysis of the MRS, possible degradation mechanisms, operating history, testing and inspection procedures, walkdown results and aspects of leak detection.

The MRS is designed to reclaim moderator inadvertently relaased from the PWS, to preclude the need to actuate the ECS for small and intermediate moderator losses and to prevent the loss of moderator or release to the environment. The system comprises a storage tank, an adapter hood, two pumps, numerous valves, and various lengths and sizes 
of piping. The tank and the adapter are fabricated from Type 304L stainless steel, as are sections of piping, numerous flanges and fittings, and the gate valves. The remainder of the piping, several flanges and fittings, and two check valves are of carbon steel (the piping is also galvanized). The material of the three-way valve, the ball valves and the control valves is Type 316 stainless steel. The sump pumps are cast iron. Design temperatures are $100^{\circ} \mathrm{F}$ for the recovery tank, $200^{\circ} \mathrm{F}$ for the carbon steel piping and $250^{\circ} \mathrm{F}$ for the adapter, the stainless steel piping and the stainless steel valves. The report provides design details on the various components, specifications for the materials, fabrication and inspection information, and the fluid chemistry of the moderator in the "clean" condition (that which the storage tank and stainless steel piping will contain during normal operation.

As part of the structural integrity assessment, the report reviews the potential for material degradation by the following mechanisms:

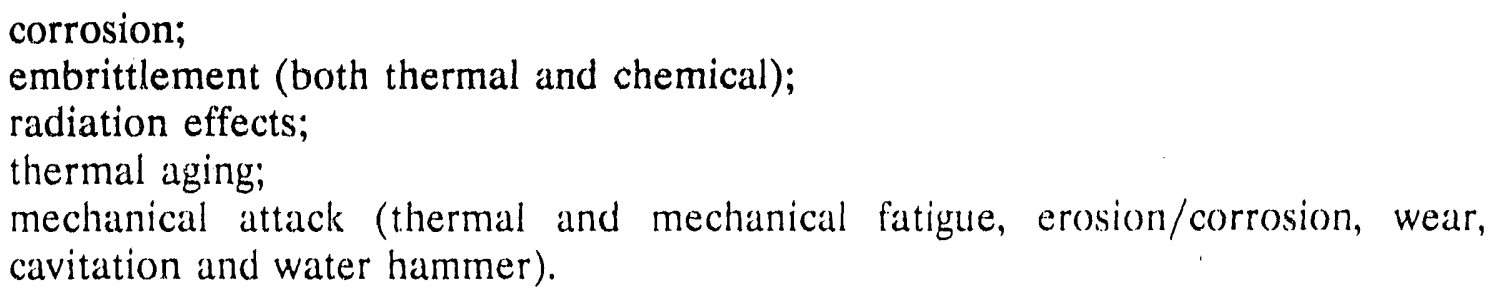

In assessing the potential of corrosion processes to degrade the materials of construction of the MRS, reference is made to [4] which is the subject of an independent review in Appendix A of this present document. With respect to the MRS, it is concluded that the majority of the corrosion processes discussed in [4] have a minimal to no predicted impact on its structural integrity. Mild concern is expressed about the potential for pitting corrosion in one specific location (U leg near the water seal flange) and identifies the need for periodic in-service inspection of the interface in question. The present reviewer concurs with the above assessment of the susceptibility of the MRS to degradation by corrosion. The carbon steel piping in the MRS is normally dry and therefore unlikely to experience any significant corrosion, including pitting attack. Within the wetted portions of the stainless steel lines, only at the identified location is there any possibility of oxygen becoming available and thus introducing a potential for pitting.

The phenomenon of thermal embrittlement in both the carbon steels and the stainless steels requires temperatures of $500^{\circ} \mathrm{F}$ and higher, well in excess of those experienced in the MRS. Thus thermal embrittlement is not a credible failure mechanism for this system. With respect to chemical embrittlement, the carbon steel and cast iron components of the MRS are dry during normal operation and not susceptible to this failure mechanism. Similarly, the environments (hclium and the moderator) to which the stainless steel components are exposed are particularly benign and the stresses very low. Thus these latter components will also not be susceptible to chemical embrittlement. 
The report concludes that the MRS components will not be subject to radiation damage, based on information in a source unavailable during the present review. As data on expected neutron fluences are not reproduced in the report, it is not possible to concur or disagree with this conclusion.

The report also reaches the conclusion that any thermal aging effects experienced by the MRS will be negligible and not cause any degradation. In view of the low operating temperatures of the MRS, this is a very reasonable conclusion.

The MRS is not subject to any significant thermal cycling or mechanical vibration. Thus concurrence is possible with the conclusion that neither thermal nor mechanical fatigue pose any threat to the integrity of the MRS.

The report concludes that erosion/corrosion is not a plausible degrading mechanism for the MRS. Inasmuch as the carbon steel piping is dry for most of the time and that stainless stcel is not generally considered to be susceptible to erosion/corrosion damage, this is a reasonable conclusion.

It is conceivable that debric in the sumps could cause wear in the system. However, precautions are taken to minimize this potential problem through the installation of screens. Considering, in addition, the infrequent usage of the MRS (due to its status as a standby safety system), it is reasonable to conclude that wear will not be a mechanism which will cause any degradation.

Although there is a possibility that cavitation could occur at the sump pump headers, the report concludes that, as a result of the pump design and the anticipated infrequent usage of the system, this does not pose a credible degradation mechanism in the MRS. Similarly, after reviewing the flow conditions in the MRS piping, including pressure spikes produced during startup and shutdown, the report concludes that water hammer events were sufficiently small that this phenomenon is not of concern with regard to degradation oi the system. The assessments of the degradation potential for both mechanisms appear to be reasonable.

The report provides a brief description of the fabrication and installation acceptance criteria employed for the MRS, and of the in-service inspection and testing requirements. Testing is performed on a semiannual, annual and as-required basis, dependent on the function of interest. Pipe supports are subject to an annual visual inspection and a five-year NDE program is used to check for thread integrity and crack development. In addition, instrumentation is available that would allow reactor operators to detect leaks in the MRS during other times. Although leaks have been detected in other reactor systems, none have been observed in the MRS although it should be noted that the systems have been operational only a short time. The MRS in the K reactor has also been the subject of a seismic qualification walkdown. No significant items requiring major design work were 
found but several minor observations were identified. Repair of these discrepancies is required prior to restart of the $\mathrm{K}$ reactor.

Overall, within the limited scope of the present review, it is concluded that the subject report provides a comprehensive evaluation of the structural integrity of the MRS. The conclusion presented, that the system is not susceptible to major leaks or gross rupture if all required modifications are implemented, is valid.

\section{STRUCTURAL INTEGRITY OF THE EMERGENCY COOLING SYSTEM}

The structural integrity of the ECS is discussed in [3]. The report follows the format adopted in the MRS review [2]. It provides a system description, a listing of the codes and standards employed in the design of the ECS, and summaries of the stress analysis of the ECS, possible degradation mechanisms, operating history, testing and inspection procedures, walkdown results and aspects of leak detection.

The ECS is designed as a standby accident mitigation system which permits the maintenance of a coolable core geometry in the event of an emergency. This it accomplishes by injecting light water directly into four of the six process water loops when required. The system comprises a booster pump, two ECS pumps, numerous valves, and various lengths and sizes of piping and fittings. All three pumps are cast iron. The ball valves are fabricated from Type 316 stainless steel while the check valves are, variously, from Type 304 stainless steel, ductile iron and carbon steel. All other valves are made from carbon steel. Both carbon steel and stainless steel (Types 304 and 304L) are used in the piping and pipe fittings. Some sections of the carbon steel piping are galvanized. Design temperatures are as high as $200^{\circ} \mathrm{F}$ for the carbon steel piping and $250^{\circ} \mathrm{F}$ for the stainless steel piping. The report provides design details on the various components, specifications for the materials, fabrication, testing and inspection information, and the typical chemistry of the treated cooling water to which the CWS and the ECS will be exposed. In addition, the part of the ECS known as "Polybor Header" contains a continuously recirculated solution of sodium polyborate.

As part of the structural integrity assessment, the report reviews the potential for material degradation by the following mechanisms:

corrosion;

embrittlement (both thermal and chemical);

radiation effects;

thermal aging;

mechanical attack (thermal and mechanical fatigue, erosion/corrosion, wear, cavitation and water hammer). 
The assessment of the potential for corrosion processes to degrade the materials of coristruction of the ECS focuses on those portions which are not part of the primary pressure boundary (these are included in [4], reviewed in Appendix A of the present document).

On the subject of uniform attack, the ECS integrity assessment report repecis the information presented in [4] with reference to corrosion of carbon steels and concludes that any general corrosion would proceed very slowly. Although the report omits discussion of the stainless steel piping, it is safe to conclude that these areas will be subject to even less corrosion. The report notes that general corrosion has been observed in the ECS, based on the results of $\mathrm{U} / \mathrm{T}$ inspections. In most cases, thickness losses are less than $15 \%$ of the original thickness but higher losses, up to $25 \%$, were observed in some sections in stagnant lines. Such losses are in excess of the corrosion allowances included in the design and obviously demand that action be taken to monitor thickness losses more closely in future, a recommendation which is made later in the report.

A brief description is given of the phenomenon of galvanic corrosion and it is noted that the potential exists for such attack at locations in the ECS where carbon steel and stainless steel flanges intcrface. However, it is concluded that such action will manifest itself as small leaks at gaskets and does not have the poiential for gross rupture.

The report states that crevice corrosion is possible at all valves in the ECS. There will also be a potential for it at all the flange interfaces. The report does not address the significance of the mechanism with rospect to the structural integrity of the ECS but it is apparent that monitoring of areas susceptible to crevice corrosion should be considered. However, as with the galvanic corrosion, the end resuit is likely to be a small leak rather than gross rupture.

Pitting corrosion has been observed in the ECS, particularly in carbon steel pipe sections with stagnant water conditions. The degradation resulted in small holes in the pipe but not gross rupture and the affected piping was replaced. Continuing the in-service inspection program should result in the detection of such degradation in the future.

The carbon steel piping in the ECS is not susceptible to intergranular corrosion but those sections will be which are made of Type 304 stainless steel, particularly in the vicinity of the welds. This susceptibility to intergranular corrosion is considerably reduced in locations where the low-carbon variant of this stainless steel is used. The problem exists in the PWS and in those portions of the ECS which form part of the primary pressure boundary, and the report cites [1] for details on how the problem is being handled. However, it omits discussion of the stainless steel piping in the ECS which is not part of the primary pressure boundary. These pipes are located in the addition lines together with the stainless steel check valves. There is some confusion about the environment to which these materials will be exposed. The ECS piping design summary table (Table 2.1) indicates that the lines will contain heavy water and perborate but elsewhere in the report (Section 5.1) 
it is stated that they will normally contain moist air. This confusing situation needs to be resolved.

The report demonstrates effectively that selective leaching is not a problem in the piping and components of the ECS.

The report correctly notes that stress corrosion is only possible in the stainless steel components of the ECS to degradation by corrosion. It then concludes that, as these components will only see moist air, stress corrosion is not a problem. As pointed out in a previous paragraph, there is some confusion about the environment to which the stainless steel piping and components are exposed.

The report concludes that microbiologically induced corrosion (MIC) is possible only in the river water sections of the ECS as bacteria will not survive in the sodium polyborate solution. The result of MIC is usually some general section thinning or pitting, and thus management of the plienomenon will be via the program instituted to monitor these two forms of degradation. The potential problem is thus being handled in a satisfactory manner and the possibility of it leading to gross rupture is negligible.

The report considers the potential for degradation $r$ sulting from hydrogen absorption, the consequence of which could be severe embrittlement. Although some steels are susceptible to degradation by this mechanism, the conditions necessary for this to occur (e.g., the presence of gaseous hydrogen) are absent in the ECS operating environment. Hydrogen embrittlement is thus not considered to be a credible degradation mechanism for the piping and components in the ECS.

Thermal embrittlement can occur in both the carbon steels and the stainl. ss steels if the materials are exposed to elevated temperatures. However, the temperatures required to promote thermal embrittlement are considerably in excess of those which will be experienced by the ECS during its operating lifetime, thus rendering the failure mechanism irrelevant for this system.

There is apparently no information available of the neutron fluence levels likely to be experienced by the ECS. However, the report concludes that radiation effects on the system are negligible. This conclusion is reached based on the results of evaluations which indicated that radiation damage was extremely low at locations closer to the reactor than the ECS. The cited information was not available to the present reviewer so concurrence (or otherwise) with this conclusion is not possible. Intuitively, however, one would expect it to be valid.

The report associates thermal aging with thermal embrittlement and concludes that, since the latter is not a concern (see above), thermal aging will not lead to degradation of the ECS. While it is possible to quibble about whether the carbide precipitation which occurs in the austenitic stainless steels as a consequence of thermal aging leads to 
embrittlement, the final conclusion, that any thermal aging effects experienced by the ECS will be negligible, is valid.

The ECS is not subject to any significant thermal cycling or vibration loads during normal operation. Thus it is appropriate to conclude that neither thermal nor mechanical fatigue pose any threat to the integrity of the system. The report infers that mechanicai fatigue may have been responsible for the failure of the structural support for the ECS polybor header strainer but points out the failure of this component does not compromisc the structural integrity of the ECS as a whole.

The function of the ECS as a standby system means that it is limited to significant flow only during axcident conditions or periodic testing. Such conditions are unlikely to be of sufficient duration to prompt any plausible concern for wall thinning damage induced by erosion/corrosion. Similarly, the infrequent use of the ECS minimizes concern about wear damage resulting from the presence of debris or river water sediment.

The report provides information on the fabrication, installation, acceptance testing and in-service inspection program of the carbon steel portions of the ECS but not, apparently, the stainless steel of the addition lines. Information is also provided on the operating history of the ECS, the leak detection capability and the results of seismic qualification walkdowns. As noted in previous paragraphs, evidence has been found of general and pitting corrosion in some of the ECS lines and several small leaks detected. Other incidents involved valves but were judged not pertinent to the structural integrity of these components. Incidents concerning the pumps did not involve conditions which could lead to gross rupture of the pressure boundary, although leakage was observed in some cases. Problems relative to the ECS strainer apparently have been corrected. The seismic qualification walkdowns revealed several areas in the ECS which required modifications. These are to be performed prior to restart.

Overall, within the limited scope of the present review, it is concluded that the subject report provides a compreherisive assessment of the structural integrity of the ECS. The report reaches the reasonable conclusion that the system is not susceptible to major leaks or gross rupture, assuming that all modifications required for seismic qualification are completed prior to restart. The report also notes that, although the materials of construction of the ECS are generally compatible with the fluids contained in the system, some general and pitting corrosion has been observed. Presumably this type of degradation will continue. However, adherence to the established inspection methods and operating procedures should ensure that such degradation will be effectively managed. 


\section{REFERENCES}

1. N.G. Awadalla, C.D. Cowfer, W.L. Daugherty, E.j. Maslik, Jr., G. Mertz, J.M. Morrison, D.F. Paddleford, J.W. Ray, R.L. Sindelar, K.J. Stoner and P.R. Vorkmelker, "Topical Report: Structural Integrity of the Process Water System (PWS) of the Savannah River Site Production Reactors (U)," WSRC-RP-90-559, June 30, 1990.

2. D.M. Van Vleet and G.E. Mertz, "Structural Integrity Assessment of the Moderator Recovery System K, P and L Reactors Savannah River Site (U)," WSRC-TR-90-321, September 21, 1990.

3. J.L. Kelly, A.J. Oster and G.E. Mertz, "Structural Integrity Assessment of the Emergency Cooling System K, P and L Reactors Savannah River Site (U)," WSRC-TR-90-323, September 27, 1990.

4. G.R. Caskey, R.S. Ondrejcin and K.J. Stoner, "Corrosion Processes in Reactor Systems (U)," WSRC-TR-90-318, September 25, 1990.

5. G.E. Mertz, "Water Hammer, Fatigue, Erosion-Corrosion, Embrittlement and Cavitation Induced Damage in Selected Reactor Piping Systems (U)," WSRC-TR-90)-319, September 28,1990 .

6. K.J. Stoner, G.E. Mertz, G.R. Caskey and J.A. Begley, "Fracture Assessment of Carbon Steel Piping in Cooling Water and Emergency Cooling Watar Systems (U)," WSRC-TR-90320, September, 1990. 


\section{APPENDIX A \\ REVIEW OF \\ "CORROSION PROCESSES IN REACTOR SYSTEMS" \\ (WSRC-TR-90-318)}

This report discusses the potential corrosion problems that might be (and have been) encountered in sysiem components within the cooling water system (CWS), the emergency cooling system (ECS), the supplementary safety system (SSS) and the moderator recovery system (MRS). After providing brief descriptions of each of the systems, including the materials of construction and the environments to which these materials will be exposed, the report is organized under section headings based on corrosion mode ("Uniform Attack," "Galvanic Corrosion," etc.). These sections are divided into subsections according to the reactor systems, with these subsections often subdivided into system components ("Piping," "Valves." etc.). A summary listing of active or potential corrosion modes is provided for each of the four systems, and recommendations are made concerning structural maintenance and continted structural integrity.

\section{General Comments}

The report is to be commended on its methodical and systematic presentation which makes it easy for the reader to locate the situation with regard to any particular system/corrosion mechanism combination. In addition, the nine corrosion processes discussed (including hydrogen degradation) represent all the accepted major processes which might be relevant to the systems under consideration. However, the extremely limited list of corrosion-related references prompts the reader to question of the actual depth of the analyses underlying the report. Of this list, which totals seven, five of the citations are to the Ninth Edition of the Metals Handbook. While this publication is without doubt a valuable reference work, its very nature dictates that the contents veer towards generalization in many areas. Further, the absence, in the subject report, of any real attempts to quantify, where appropriate, the effects of the corrosion processes lends support to the suspicion that perhaps a more comprehensive evaluation could have been performed.

One very minor limitation was inevitable in structuring the report with respect to the corrosion processes and that is that these processes are basically applicable only to metal components. Thus the report does not cover potential degradation of the few non-metallic components present. In particular, the performance of the rubber expansion joint bellows in the CWS would seem to be of some importance. 
Some Specific Comments

\section{Section 5.1.1 (Carbon Steel Piping)}

The report describes the uniform corrosion of carbon steel as occurring "at a rate of approximately 2 to 8 mils/year at temperatures between 22 and $100^{\circ} \mathrm{C}$ in freshwater ..." and cites a reference. This information could not be located in the cited reference.

There is discussion of the possibility of corrosion from groundwater but this is discounted because the relevant pipes in the CWS are coated, presumably with GACO though this is not clear from the text. It is then conceded that much of the GACO has disappeared, leaving only primer on the steel. Commendably, the report recommends investigation of the effect that the "lineriprimer" combination plays in the various corrosion processes. However, it would also seem prudent to review the data base available on the soil corrosion of unprotected carbon steel and to estimate possible thickness losses and pitting rates (the seminal work in this area was published by M. Romanoff in the NBS Circular 579, "Underground Corrosion," 1957).

\section{Section 6.2 (Emergency Cooling System)}

This section discusses the potential for galvanic corrosion in the ECS so it was surprising to find no mention of the fact that this system contains some galvanized steel. Unlike other many other types of coatings, breaching of the galvanized layer does not lead to enhanced corrosion of the substrate because galvanic action leads to preferential attack of the coating itself.

\section{Section 7.0 (Crevice Corrosion)}

The report is correct to identify this as a potential problem. It could be the most common corrosion process taking place and steps must be taken to monitor critical areas.

\section{Section 8.0 (Pitting Corrosion)}

It is stated that "stainless steels are more susceptible to pitting corrosion than carbon steels" but no supporting evidence is provided. It is very much to be doubted if this is true and the statement leaves an erroneous impression of the corrosion resistance of the stainless steels.

\section{Section 8.1.1 (Piping)}

Pitting is likely to be a common degradation mode on the exterior of the piping and the report is correct to recommend regular inspection. However, the evaluation should have include at least an attempt to quantify the phenomenon. Simple models do exist and 
estimates can be made (see, for exampie, the rates of pitting due to soil corrosion developed in the NBS Circular 579 mentioned above).

\section{Section 9.1.3 (Expansion Joints)}

The report is correct to recommend reevaluation of the inservice inspection plan for the CWS expansion joint bellows. However, the problem is really intergranular stress corrosion cracking, not simple intergranular corrosion as it is normally visualized.

\section{Section 12.1 (Cooling Water System)}

There is no discussion of potential microbiologically induced corrosion on the external surfaces of the underground piping.

\section{Conclusions}

Notwithstanding the above-stated concerns, it is concluded that this report represents a comprehensive summation of the potential for corrosion-based degradation in the reactor systems. Low operating temperatures and the relatively non-aggressive environments render the systems under review not susceptible to gross rupture or failure. The report correctly identifies areas where corrosion processes will be active and makes a dozen recommendations which, if implemented, will contribute to the continued integrity of the systems under review. 


\title{
APPENDIX B
}

\author{
Review of \\ "Water Hammer, Fatigue, Erosion-Corrosion, Embrittlement and Cavitation Induced \\ Damage in Selected Reactor Piping Systems" \\ WSRC-TR-90-319
}

This report describes evaluations of several degradation mechanisms applicable to the cooling water system (CWS), the emergency cooling system (ECS) and the supplementary safety system (SSS). The subject degradation mechanisms (water hammer, thermal and mechanical fatigue, erosion-corrosion, thermal and chemical embrittlement, and cavitation) are additional to those such as corrosion and radiation effects which are treated in other reports. The results of the assessments are presented in summary sections in the main. report for each of the mechanisms under review. For more details on the evaluations, the reader is referred to a series of Attachments to the main document. The overall assessment and the conclusions derived are presented in a short summary section.

\section{Comments}

The discussion of the susceptibility of the CWS and ECS to water hammer begins with descriptions of seven mechanisms which have occurred in commercial nuclear power plants and which can have a severe effect on a system, then it proceeds to evaluate the systems in question. This evaluation involves a review of the operating history of the reactors to determine how many water hammer incidents occurred and what were the mechanisms responsible. This is followed by a walkdown of the two systems of interest to search for visible signs of past unreported events which caused no significant damage. The CWS and ECS system design are then reviewed, as are the system operating procedures and the system test, inspection and maintenance procedures. The report concludes that, as long as procedures are followed, the susceptibility of the two systems to water hammer is low. Some suggestions are provided that, if implemented, would further lower this susceptibility. The report conclusions appear to be based on an extensive data base and the result of indepth appraisal of the system characteristics. This reviewer concurs with the evaluation based on the data presented.

Evaluation of the susceptibility of the CWS and ECS to thermal and mechanical fatigue is presented in less detail than that on water hammer and most of the analyses and examination data are contained in referenced documents not available to this reviewer. Thus it is not appropriate to comment on the report's principal conclusion that fatigue is unlikely to be a problem in these two systems. 
The report also concludes that the CWS and ECS piping and components should not experience wall thinning caused by classical erosion-corrosion, as, for example, was experienced at the Surry commercial nuclear power plant. This conclusion was reached after a comparison of the parameters (material, coolant temperature, flow velocity, chemistry, etc.) which are normally associated with accelerated erosion-corrosion with the materials and operating parameters of the two systems. Metallurgical and inspection reports were also reviewed to determine if there had been any evidence of wall thinning due to erosion-corrosion in the past. This reviewer concurs that erosion-corrosion is unlikely to be a problem in the CWS and ECS, and supports the recommendations for supplementing the existing inspection program. In particular, concern is shared relative to the problems which arise about the loss of integrity of the liner material in the GACO-lined pipe.

This reviewer also concurs with the conclusion that thermal embrittlement is extremely unlikely to occur in any of the materials which comprise the CWS and the ECS. The design and operating temperatures of the two systems are much lower than those necessary to promote metallurgical reactions which lead to embrittlement of these materials.

In evaluating the ECS and the SSS in terms of susceptibility to chemical embrittlement, the report concentrates on two possible degradation mechanisms - hydrogen embrittlement and corrosion fatigue. By comparing the chemical and physical conditions extant in the two systems with those required to promote hydrogen embrittlement, it is effectively demonstrated that this particular phenomenon is not a credible failure mode for either the carbon steels or the stainless steels in either the ECS or the SSS. On the subject of corrosion fatigue, it is difficult to think of it in terms of an embrittlement phenomenon. However, it is certainly a potential degradation mechanism which must be considered. The report, while conceding that a reduction in fatigue strength due to corrosion effects is possible for the carbon steels and the stainless steels, concludes that this is unlikely to be a primary failure mode. While intuitively there is concurrence with this opinion, on account of the relatively benign environments involved and the standby nature of both systems, the evaluation would have been strengthened by the inclusion of some data on the possible alternating stress conditions in select components and a comparison of these data with established design fatigue limits. Another omission from the two Attachments on susceptibility to chemical embrittlement is consideration of the possibility of caustic embrittlement. Given the chemical conditions usually required to promote caustic embrittlement (particularly, a high concentration of caustic), it is an extremely unlikely mode of degradation in this case, but the same may be said for many of the degradation modes evaluated for these systems.

Cavitation involves a sequence of pressure decrease followed by sudden pressure increase and can lead to erosion and severe wall thinning, which, in turn, can result in breaching of the pressure boundary. The report discusses this phenomenon and reviews the operation and inspection histories of the CWS and ECS to find if there were any indications of cavitation damage. Qualitative and quantitative evaluations were conducted of the pumps, throttle valves and orifices in order to determine their cavitation potentials. 
Cavitation has not been reported as a problem during past operation of the plants and the evaluations of cavitation potentials indicated it should not be a problem in these systems. However, the report recommends that better documentation of the avalable NPSH (Net Positive Suction Head) calculations be generated for all the pumps in the two systems. Also, where data did not exist on site, they should be obtained from the pump manufacturer and documented. Within the limited scope of the present review, the conclusions and recommendations of the report appear reasonable. 


\author{
APPENDIX C \\ REVIEW OF \\ "Fracture Assessment of Carbon Steel Piping in \\ Cooling Water and Emergency Cooling Water Systems" \\ WSRC-TR-90-320
}

This report describes a re-evaluation of the adequacy of the carbon steel piping in the cooling water (CWS) and emergency cooling (ECS) systems for service at a minimum operating temperature of $40^{\circ} \mathrm{C}$. A brief description is provided of the fracture assessment methodology and the results of three previous studies summarized. Mechanical property data (tensile, Charpy Vnotch impact, and static and dynamic fracture toughness) obtained from samples of representative pipe material are presented, together with a review of the general condition of the piping. The report includes a brief section on stresses in the piping followed by an extensive description of how the structural integrity assessment was performed and a discussion of the limitations of the analysis.

\title{
General Comments
}

An in-depth assessment of the stress analysis performed and the application of linear elastic fracture mechanics to calculate allowable flaw sizes is beyond the scope of the present review but it should be noted that the report itself concedes that the analysis is not complete and there is consequently some uncertainty concerning the calculated allowable flaw sizes. 


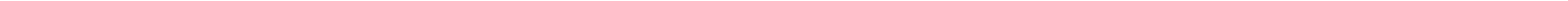

